\title{
The Nuclease from Gram-Negative Bacteria Serratia Marcescens is Weakly Cytotoxic at Therapeutic Doses
}

\section{Malanyeva Albina G, Salikhova T, Rizvanov AA and Filimonova MN* \\ Institute of Fundamental Medicine and Biology, Kazan Federal University, Russia}

*Corresponding author: Dr. Maria Filimonova, Institute of Fundamental Medicine and Biology, Kazan Federal University, Kazan, Tatarstan, Russia; Email: maria.filimonova@kpfu.ru

\section{Research Article \\ Volume 6 Issue 1}

Received Date: November 29, 2020

Published Date: January 22, 2021

DOI: $10.23880 /$ oajvsr-16000205

\section{Abstract}

The nuclease from S.marcescens heads a family of homological nonspecific nucleases. Its cultivation features, structure, mechanism of action, some physical, chemical and biochemical properties are well studied. It is presented by two isoforms, differing by $\mathrm{N}$-terminal fragment and some properties. The nuclease demonstrated a cancer suppressing effect in mice. It is a key component of the anti-rabies composition which increases survival of the infected mice. It is similar by its efficiency to Pulmozyme ${ }^{\circledR}$ that is used for airway cleansing during the treatment of pulmonary diseases.

The aim of the study was to analyze a cytotoxic effect of $S$. marcescens nuclease and its separate isoforms at different concentrations. To determine the cytotoxicity we used MTT assay and human cell cultures of colorectal cancer -HCT 116, breast cancer MCF-7 and normal skin fibroblasts.

Results show that the nuclease demonstrates a weak cytotoxic effect at the amounts of $0.2-25 \mu \mathrm{g}$ per $1 \mathrm{ml}$ of the cell culture medium that is close to its therapeutic doses. This effect is not connected with the loss of the enzymatic activity. The isoforms are similar by their IC50.

Keywords: Serratia Marcescens nuclease; Sma Nuc; Isoforms Sm1 And Sm2; Cytotoxity; Pulmozyme; Anti-Rabies Activity; MTT-Test; Human Colorectal Cancer Cell Culture; Human Breast Cell Cancer; Human Skin Fibroblasts

\section{Introduction}

Serratia marcescens nuclease (EC 3.1.30.2) originates from Gram negative bacteria Serratia marcescens and heads a family of homological nonspecific nucleases which are widely spread in the world [1]. S. marcescens nuclease is the most studied nuclease in this family. Its cultivation features, structure, mechanisms of action, as well as some physical, chemical and biochemical properties are well studied [2-20] and represented in such famous data banks as SCOP, RCSB, Brenda. It is presented in two major isoforms, $\mathrm{Sm} 1$ and $\mathrm{Sm} 2$, differing by $\mathrm{N}$-terminal three-peptide fragment, pIs and a few biochemical properties $[13,16]$.
The nuclease has broad actual and potential utilities due to its potent digestive activity towards both DNA and RNA (Table 1). Under a trade name Benzonase it is manufactured by a few biochemical companies. Due to supposed antiviral activity the nuclease was used in beekeeping in order to prevent viral infection of insects [21]. S. marcescens nuclease is a key component of the composition demonstrating antirabies activity. Injection of this composition in to a mouse's infection site in two hours after the mouse has been infected with rabies, resulted in $30 \%$ increased survival of the infected animals if to compare with the animals without the nuclease treatment [22]. Recently $S$. marcescens nuclease was found to be highly effective on sputum DNA [23]. Its efficiency 


\section{Open Access Journal of Veterinary Science \& Research}

was comparable with Pulmozyme ${ }^{\circledR}$ which is intensively used for treatment of pulmonary diseases such as chronic bronchitis, Kartagener's syndrome, chronic obstructive pulmonary disease, lobar atelectasis, bronchiectasis, and cystic fibrosis because of degradation of DNA in sputum for airway cleansing. We revealed that while demonstrating similar to Pulmozyme ${ }^{\circledR}$ efficacy the nuclease amount can be several times less than that of Dornase alpha, the active component of Pulmozyme ${ }^{\circledR}$. Earlier the nuclease was found to have an anticancer effect. After intraperitoneal injection in to white mice the nuclease at a dose of $0.25 \mu \mathrm{g} / \mathrm{g}$ slowed down development of the intraperitoneal Ehrlich carcinoma by $50 \%$ [24].

\begin{tabular}{|c|c|c|c|c|c|c|}
\hline $\begin{array}{c}\text { The used } \\
\text { model }\end{array}$ & Effect & Efficiency & $\begin{array}{c}\text { Purity of the } \\
\text { nuclease }\end{array}$ & $\begin{array}{c}\text { The type } \\
\text { of isoform }\end{array}$ & $\begin{array}{c}\text { Effective } \\
\text { amount }\end{array}$ & Reference \\
\hline $\begin{array}{c}\text { Unbreded } \\
\text { white mice }\end{array}$ & $\begin{array}{c}\text { Suppression } \\
\text { of cancer } \\
\text { growth }\end{array}$ & $\begin{array}{c}\text { Inhibition of intraperitoneal } \\
\text { Ehrlich carcinoma by more than } \\
50 \%\end{array}$ & Highly purified & Unknown & $\begin{array}{c}0.25 \mu \mathrm{g} / \mathrm{g} \\
\text { of mouse }\end{array}$ & {$[24]$} \\
\hline $\begin{array}{c}\text { Unbreded } \\
\text { white mice }\end{array}$ & $\begin{array}{c}\text { Antirabies } \\
\text { activity }\end{array}$ & $\begin{array}{c}\text { Increased survival of infected } \\
\text { mice by more than } 30 \%\end{array}$ & Homogeneous & Sm1 & $\begin{array}{c}1.0 \mu \mathrm{g} / \mathrm{g} \text { of } \\
\text { mouse }\end{array}$ & {$[22]$} \\
\hline $\begin{array}{c}\text { In vitro, } \\
\text { purulent- } \\
\text { mucous } \\
\text { sputum }\end{array}$ & $\begin{array}{c}\text { Degradation } \\
\text { of DNA in } \\
\text { sputum }\end{array}$ & $\begin{array}{c}\text { Manifestation similar with } \\
\text { Pulmozyme® hydrolytic activity } \\
\text { on sputum DNA at standard for } \\
\text { Pulmozyme } ® \text { conditions }\end{array}$ & Homogeneous & Sm1\&Sm2 & $\begin{array}{c}\mu \mathrm{pg} / \mathrm{ml} \text { of } \\
\text { sputum }\end{array}$ & {$[23]$} \\
\hline
\end{tabular}

Table 1: The amounts of S.marcescens nuclease and its isoforms required for therapeutic effects.

However later we found the nuclease at approximately the same concentration $(0.23 \mu \mathrm{g} / \mathrm{g}, 600 \mathrm{U} / \mathrm{ml})$ did not influence viability of tumor cells when in vitro the rat hepatoma cell culture (H4-II-E-C3) was incubated with the nuclease solution [25]. Simultaneously examination of the nuclease cytotoxicity (MTS-test) at the concentration of $0.4 \mu \mathrm{g} / \mathrm{ml}$ and less ones revealed its weak influence on the activity of mitochondrial dehydrogenases of human embryonic kidney cells that suggested a weak cytotoxic effect at the tested amounts.

Inconsistency in anticancer action of S.marcescens nuclease in vivo and in vitro at near the same concentrations together with its weak cytotoxicity, from one side, and, from another side, its therapeutic efficacy, especially similar with Pulmozyme ${ }^{\circledR}$, induced us to examine additionally the cytotoxic action of $S$. marcescens nuclease.

The aim of the study was to analyze a cytotoxic effect of S.marcescens nuclease and its separate isoforms at the different concentrations. We studied the nuclease cytotoxicity at the enzyme amount close to its therapeutic doses and at the ten-fold higher amount in order to determine its IC50, also we compared the nuclease isoforms by their cytotoxicity, and compared cytotoxic effect of the nuclease towards malignant and non-malignant cells.

\section{Materials and Methods}

All reagents were purchased from commercial sources, unless stated otherwise - magnesium sulfate, and DNA from herring testes (type XIV) were purchased from SigmaAldrich, MTT - Roche applied sciences (Cat. No. 11465007 001). All the described reagents were used without further purification. Bacterial strain W1050 of S. marcescens was kindly provided by Prof. Michael Benedik (University of Houston, USA).

Purification of $S$. marcescens nuclease was carried out as was described earlier [26]. The procedure was based on routine preparation of the culture medium and fractional salt precipitation of the crude nuclease, the dialysis, and cation exchange chromatography with NGC Discover chromatography system using UNO S12 column (Bio-Rad, USA). The DNA-degrading enzymatic activity in the collected fractions was tested as previously described [11]. The isoforms were separated as described earlier [13].

The purity of the nuclease from the peak fractions was analyzed by denaturing sodium dodecyl sulfate polyacrylamide gel electrophoresis (SDS-PAGE) using 12\% gel and additionally by matrix-assisted laser desorption/ ionization time-of-flight (MALDI-TOF) mass spectrometry on UltrafleXtreme (Bruker Daltoniks, Germany) using alphacyano-4-hydroxycinnamic acid (HCCA) as a matrix that was previously noted [26]. The purity of the nuclease isoforms was characterized as previously described [13].

The purified nuclease or the isolated isoforms were then dialysed against distilled water and lyophilized. After that 1 mg of each lyophilized nuclease preparation was dissolved with $1 \mathrm{ml}$ of physiological saline, $0.85 \%$ water solution of 


\section{Open Access Journal of Veterinary Science \& Research}

$\mathrm{NaCl}$, and used to study the cytotoxicity. Concentration of the nuclease solutions was calculated based on the absorption of protein solution at $280 \mathrm{~nm}$ and molar extinction coefficient of $47292 \mathrm{M}-1 / \mathrm{cm}^{2}$ [27].

\section{Determination of the Nuclease Cytotoxicity}

To determine the nuclease cytotoxicity we used a widely explored MTT assay. A procedure for analyzing the nuclease cytotoxicity was based on the previously published assay [28]. To compare cytotoxicity towards malignant and nonmalignant cells we used human colorectal cancer culture - HCT 116 (ATCC® CCL-247 ${ }^{\mathrm{TM}}$ ) and human skin fibroblasts (HSF) culture that was previously isolated from skin of a healthy donor. All subjects gave written informed consent in accordance with the Declaration of Helsinki. The protocol was approved by Ethic Expert Committee of Kazan Federal University (Republic of Tatarstan, Russian Federation). To compare cytotoxicity of the nuclease isoforms and determination of IC50 we used human breast cancer culture MCF-7. MCF-7 cell line was obtained from ATCC.

The cell cultures were incubated in DMEM medium supplemented with $10 \%$ FBS, $2 \mathrm{mM} \mathrm{l-glutamine,} 100 \mu \mathrm{g} /$ $\mathrm{ml}$ penicillin and $100 \mathrm{U} / \mathrm{ml}$ streptomycin. The cells were seeded in 96-well plates at the density of 1000- 2000 cells per well (MCF-7 culture) or 3000 cells per well (HSF- or HCT 116 -cultures) and allowed to attach overnight under humid atmosphere containing $5 \% \mathrm{CO}_{2}$ at $37^{\circ} \mathrm{C}$. Then the culture medium was gently removed and changed with the fresh medium containing S.marcescens nuclease at a final protein concentration as shown in Table 2. Cells were cultured for $72 \mathrm{~h}$ at $37{ }^{\circ} \mathrm{C}$ and $5 \% \mathrm{CO}_{2}$. Grown cells were washed with fresh medium and subjected to conventional MTT assay. The colored product of MTT reduction by viable cells was detected on Infinite 200 PRO analyzer (TECAN) at 565 (HSF- or HCT 116 -culture) or 555 nm (MCF-7 culture). The reference wavelength was 670 or $750 \mathrm{~nm}$ respectively. Each experiment was performed in 3 replicates.

To make sure that the nuclease activity has not changed both in the culture medium itself and due to the action of the cell culture for $72 \mathrm{~h}$ - incubation we determined DNase activities of culture mediums with and without nuclease (used as a control on the medium influence) as well as of culture mediums containing the cell cultures with and without nuclease (used as a control on the culture influence) at the beginning $(0 \mathrm{~h})$ and at the end $(72 \mathrm{~h})$ of the cultures incubation with the nuclease.

\begin{tabular}{|c|c|c|c|c|}
\hline $\begin{array}{c}\text { An isoforms of the } \\
\text { nuclease }\end{array}$ & $\begin{array}{c}\text { The nuclease } \\
\text { concentration, } \boldsymbol{\mu g} \\
\mathbf{/ m l}\end{array}$ & $\begin{array}{c}\text { DNase activity, } \\
\mathbf{U} / \mathbf{m l}\end{array}$ & $\begin{array}{c}\text { The type of cell } \\
\text { culture }\end{array}$ & $\begin{array}{c}\text { Final concentration of the } \\
\text { nuclease in the assay mixture, } \\
\boldsymbol{\mu g} / \mathbf{~ m l}\end{array}$ \\
\hline Sm1+Sm2 & 25 & 121280 & $\begin{array}{c}\text { human skin fibroblasts } \\
\text { HSF human colorectal } \\
\text { cancer HCT }\end{array}$ & 2.5 \\
\hline Sm1 & 425 & 1912000 & human breast MCF-7 & 42.5 \\
\hline Sm2 & 383 & 1456000 & human breast MCF-7 & 38.3 \\
\hline
\end{tabular}

Table 2: Characterization of the nuclease preparations used for determination of the cytotoxicity.

The DNase activity was determined using 96-well plate assay modified from that described previously The wells of microwell dish were filled with $100 \mu \mathrm{l}$ of the assay mixture [29]. A $50 \mu \mathrm{l}$ sample of the tested medium respectively containing or not the appropriate amount of the nuclease was applied into the well of each row corresponding (see remarks at the left hand side of the plate) to the nuclease concentration at the tested medium. As each experiment was performed in 3 replicates, 3 wells in each row were filled with samples of the appropriate repetitions.

The plate was covered with the foil and incubated at $37^{\circ} \mathrm{C}$. After incubation for $15 \mathrm{~min}$ the plate was placed on a UV light box and photographed. The loss of fluorescence due to DNA degradation was visualized and each sample was compared with the others containing or not the nuclease and cell cultures.

\section{Results and Discussion}

\section{Purification of $S$. Marcescens Nuclease}

Using the earlier published protocol for purification of $S$. marcescens nuclease [26] we obtained the purified enzyme exhibiting high level of activity. Homogeneity of the nuclease preparation was verified by SDS-PAGE that indicated a single protein band with an apparent molecular mass near $30 \mathrm{kDa}$. The full-scan MALDI-TOF mass spectrum of the nuclease preparation demonstrated a series of multicharged ions at $\mathrm{m} / \mathrm{z}$ 5226.100-26693.261 that all belong to one single protein with molecular mass matching the $S$. marcescens nuclease [13]. The results of both SDS-PAGE and 


\section{Open Access Journal of Veterinary Science \& Research}

MALDI-TOF experiments, together with enzymatic activity measurements, confirm high purity of the isolated protein.

Examination of cytotoxic effect of S.marcescens nuclease at therapeutic doses toward malignant and non-malignant cells. The nuclease amounts for its therapeutic effects are $0.02-34 \mu \mathrm{g} / \mathrm{ml}$ (Table 1 ). The anti-rabies activity was found with Sm1 isoform at $1.0 \mu \mathrm{g} / \mathrm{g}$ of the mouse. For degradation of DNA in sputum the nuclease preparation containing Sm1 and Sm2 isoforms was effective at the concentration of $0.02-34 \mu \mathrm{g} / \mathrm{ml}$ of sputum. Suppression of the cancer growth was observed at the nuclease concentration of $0.25 \mu \mathrm{g} / \mathrm{g}$ of the mouse. So to verify cytotoxicity of $S$. marcescens nuclease we used the enzyme preparation containing Sm1 and Sm2 isoforms at the concentration of $25 \mu \mathrm{g} / \mathrm{ml}$ and DNase activity of $121280 \mathrm{U} / \mathrm{ml}$ for $1 \mathrm{~h}$. The examination demonstrated its weak influence on the activity of mitochondrial dehydrogenises in the human skin fibroblasts that was verified by slight variation in the absorption of the assay mixture at $565 \mathrm{~nm}$ (Figure 1A). Incubation of the cell culture in the presence of $0.02-2.5 \mu \mathrm{g}$ of the nuclease per $1 \mathrm{ml}$ of the culture medium diminished the absorption by 5-8\%. These data suggested a little cytotoxic effect of S.marcescens nuclease and confirmed a previously published result reporting a little cytotoxic effect of the isoform Sm1 determined with MTS-test at the nuclease concentrations of $0.02-0.4 \mu \mathrm{g} / \mathrm{ml}$ of the human embryonic kidney (HEK293) cells culture [22].

A comparative analysis of the nuclease cytotoxicity towards malignant and non-malignant cells showed some difference in variations in the resulted absorptions of the assay mixtures at $565 \mathrm{~nm}$ (Figure 1, panels A and B). Although the HCT cell culture was incubated with the same nuclease preparation and at the same conditions as described above for HSF culture the absorption characterizing the activity of mitochondrial dehydrogenases diminished by $12-17 \%$ (Figure 1, panel B) against 5-8\% (Figure 1, panel A) for HSF cell culture.

In order to make sure that S.marcescens nuclease has not lost the enzymic activity for $72 \mathrm{~h}$-incubation with the cell cultures as well at the culture medium itself we determined DNase activities in the mediums at the beginning $(0 \mathrm{~h})$ and the end $(72 \mathrm{~h})$ of cultures incubations with S.marcescens nuclease.

Determination of the DNase activity in the culture medium in the absence and in the presence of cell cultures at the beginning and at the end of the incubation with $S$. marcescens nuclease was based on quenching luminescence of ethidium bromide incorporated in DNA of the appropriate assay mixture. The results of the determining DNase activities are shown at Figures 2 and 3.

As can be seen from Figures 2 and 3, S.marcescens nuclease is active both in the culture medium itself (columns $1-3$, panels A and B) and in the presence of cell cultures (columns 4-6, panel A and -7-9, panel B), that is displayed by the quenching luminescence in the wells due to DNA digestion at the assay mixture in the wells. In the absence of S.marcescens nuclease, the DNase activity in the culture medium itself (columns 7-9, panel A and - 4-6, panel B) and in the presence of the cell cultures (columns 10-12 panels A and B) was not detected, which was manifested by the fluorescence of undigested DNA in the wells.

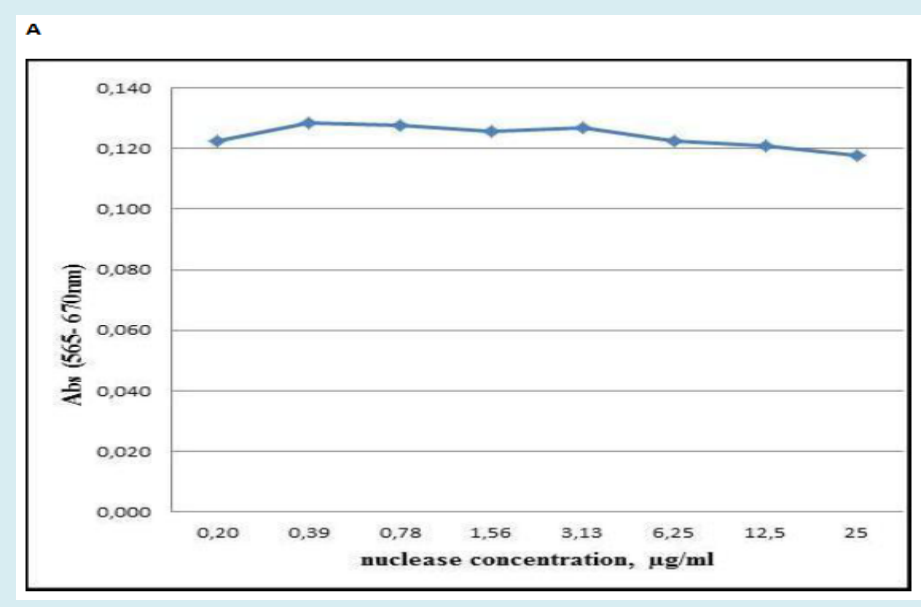

B

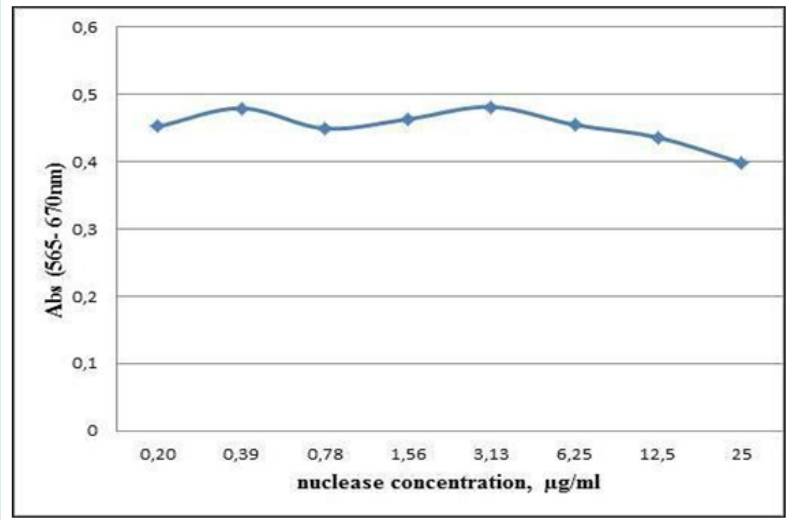

Figure 1: Cytotoxic effect of $S$. marcescens nuclease towards human skin fibroblasts cell culture HSF (panel A) and human colorectal cancer cell culture HCT (panel B). Variation of absorption at $565 \mathrm{~nm}$ (Y-axis) characterizing the activity of mitochondrial dehydrogenases upon the addition of the nuclease to final concentrations at the culture medium which are displayed at X-axis. 


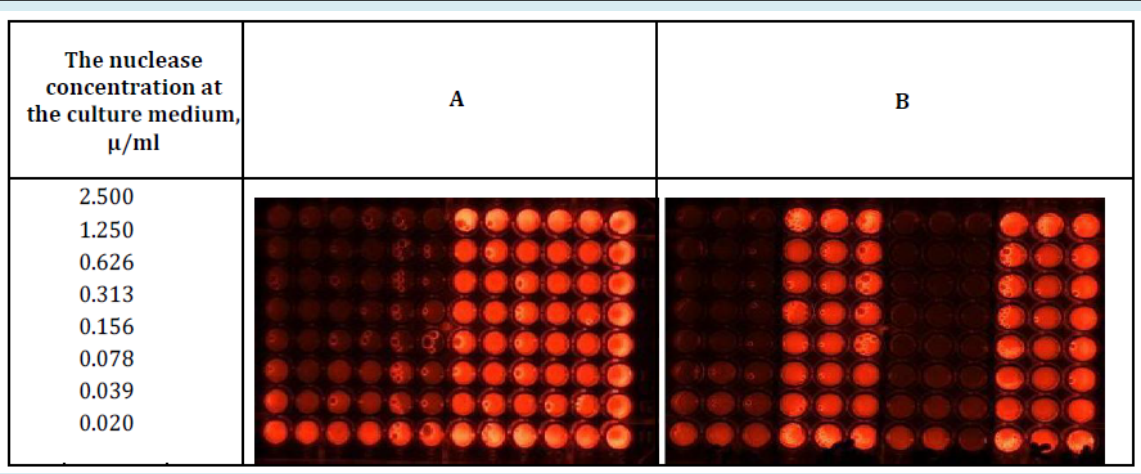

Figure 2: Determination of the DNase activity at the beginning (panel A) and the end (Panel B) of incubation of HSF cell culture (Columns 4-6,10-12 and $7-12$, Panels A and B respectively) and the culture mediums without the cells (Columns 1-3,7-9 and 1-6, Panels A and B respectively). In the presence of $S$. marcescens nuclease (Columns 1-6 and 1-3, 7-9, Panels A and B respectively) and in the absence (Columns 6- 12 and 4-6, 9-12 Panels A and B, respectively) of $S$. marcescens nuclease.

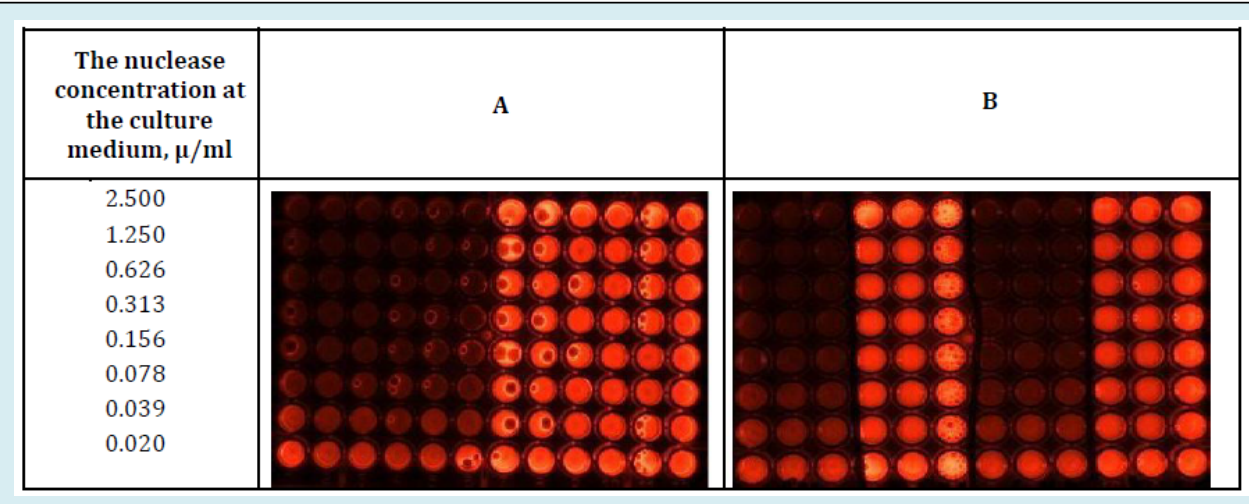

Figure 3: Determination of the DNase activity at the beginning (panel A) and the end (Panel B) of incubation of HCT cell culture (Columns 4-6,10-12 and 7-12, Panels A and B respectively) and the culture mediums without the cells (Columns 1-3,79 and 1-6, Panels A and B respectively). See explanation to Figure 2.

15 min incubation of the assay mixture in the wells was sufficient for the development of DNase activity at the nuclease concentration of $0.039-2.5 \mu \mathrm{g}$ per $1 \mathrm{ml}$ of the cultures mediums (rows 1-7) in both the presence (columns 4-6, panel A and -7-9, panel B) and the absence (columns 1-3 panels $A$ and $B$ ) of the cell cultures.

At both the beginning (panel A) and the end (panel B) of the nuclease incubations in the cultures mediums in the presence (columns 4-6, panel A and -7-9, panel B) and absence (columns 1-3, panels A and B) of cell cultures the luminescence was quenched by identical amounts of the nuclease corresponding to $2.5 ; 1.25 ; 0.626 ; 0.313 ; 0.156$; $0.078 ; 0.039 \mu$ g (rows $1 ; 2 ; 3 ; 4 ; 5 ; 6 ; 7$ respectively) per $\mathrm{ml}$ of the cultures mediums which indicated no loss of DNase activity in $S$. marcescens nuclease after the $72 \mathrm{~h}$ incubations.

As figures 2 and 3 are very similar, we suggest that malignancy of the cell culture was irrelevant for manifesting DNase activity of S.marcescens nuclease during the incubation.

\section{Comparative Analyses of Cytotoxic Effect of S.Marcescens Nuclease Isoforms}

As shown in Section The Examination of cytotoxic effect of S.marcescens nuclease at therapeutic doses toward malignant and non-malignant cells, the preparation of $S$. marcescens nuclease containing isoforms $\mathrm{Sm} 1$ and $\mathrm{Sm} 2$ at the concentration of $25 \mu \mathrm{g} / \mathrm{ml}$ and DNase activity of 121 $280 \mathrm{U} / \mathrm{ml}$ for $1 \mathrm{~h}$ demonstrated relatively weak and similar to each other cytotoxic effect towards HSF- and HCT cells. Previously a weak cytotoxic effect of isoform Sm1 of $S$. marcescens nuclease on human embryonic kidney cells was observed with MTS test [25]. Data on the cytotoxic effect of the isoform Sm2 are not known.

For comparative analyses of cytotoxic effect of isoforms Sm1 and Sm2 we used two preparations, containing $425 \mu \mathrm{g}$ $/ \mathrm{ml}$ of the isoform Sm1 and $383 \mu \mathrm{g} / \mathrm{ml}$ of the isoform Sm2 
(Table 2). The result is presented at Figure 4 where optical signal of formazan after reduction of tetrazolium salt (3-(4,5dimethylthiazol-2-yl)-2,5-diphenyltetrazolium bromide (MTT) by metabolically active MCF-7 cells, preliminarily incubated for $72 \mathrm{~h}$ with isoforms Sm1 and Sm2 (panels A and $B$, respectively), is shown.

A

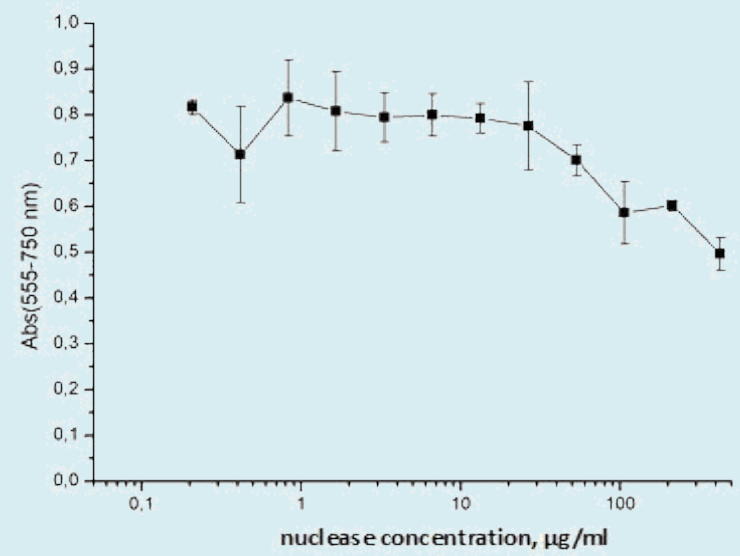

B

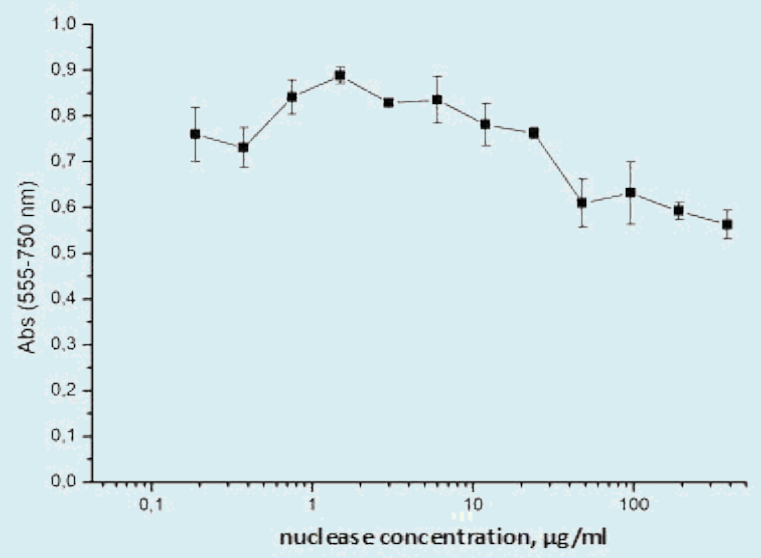

Figure 4: Cytotoxic effect of isoforms of $S$. marcescens nuclease towards human breast cell culture MCF-7. Variation of absorption at $555 \mathrm{~nm}$ (Y -axis) characterizing the activity of mitochondrial dehydrogenases upon the addition of the isoform Sm1 (panel A) or Sm2 (panel B) to final concentrations at the culture medium which are displayed at $\mathrm{X}$-axis.

As can be seen from Figures 4 , at a concentration of $0.02-2.6 \mu \mathrm{g} / \mathrm{ml}$ or $0.02-2.3 \mu \mathrm{g} / \mathrm{ml}$ of isoforms $\mathrm{Sm} 1$ or $\mathrm{Sm} 2$, respectively, per $1 \mathrm{ml}$ of the culture medium both isoforms demonstrated a weak influence on the activity of mitochondrial dehydrogenases of human breast cell culture
MCF-7.

The variations in the absorption at $555 \mathrm{~nm}$ of the assay mixtures were slight. The absorption diminished by 5-7 \% for isoforms Sm1 (Fig.4 panel A) or less than 14\% - for Sm2. (Fig.4 panel B). These data were close to the results observed at the cell cultures of human skin fibroblasts or human colorectal cancer (Fig. 1 panels A and B), and all together demonstrated a weak cytotoxicity of S.marcescens nuclease at the therapeutic amounts. At the same time a 16 -fold increasing concentration of each isoform in the cell medium decreased the absorption at $555 \mathrm{~nm}$ by about $40 \%$. The obtained results allowed us to calculate IC50 that were $35,8 \pm 3,1 \mu \mathrm{g} / \mathrm{ml}$ for Sm1 isoform and 36,7 $\pm 6,8 \mu \mathrm{g} / \mathrm{ml}$ for $\mathrm{Sm} 2$ isoform. These data allow us to report of similarity of isoforms Sm1 and Sm2 of S.marcescens nuclease by cytotoxicity towards the human breast cell cancer MCF-7 and suspect their similarity by cytotoxicity towards other cell line cultures.

\section{Conclusion}

Analysis of a cytotoxic effect of S.marcescens nuclease and its isoforms Sm1 and $\mathrm{Sm} 2$ specifies the following.

S.marcescens nuclease represented by two major isoforms $\mathrm{Sm} 1$ and $\mathrm{Sm} 2$ demonstrates a weak cytotoxic effect at the concentration of $0.2-25 \mu \mathrm{g} / \mathrm{ml}$ which is close to the therapeutic doses used for cancer suppressive action, antirabies- and mucolytic activities.

A relatively weak cytotoxic effect of $S$.marcescens nuclease is not connected with the loss of the enzymatic activity which is not changed for $72 \mathrm{~h}$ incubation in the cultures medium in both the absence and the presence of cultured cells.

The isoforms Sm1 and Sm2 of S.marcescens nuclease are similar by cytotoxic effect and characterized by the same IC50 values towards the human breast cancer cells MCF-7.

\section{Conflicts of Interest}

The authors declare no conflicts of interest. The submitted work was carried out in the absence of any personal, professional or financial relationships that could potentially be construed as a conflict of interest.

\section{Acknowledgments}

This work was funded by the subsidy 0671-2020-0058 allocated to Kazan Federal University for the state assignment in the sphere of scientific activities. Kazan Federal University was supported by the Russian Government Program of Competitive Growth. 


\section{Open Access Journal of Veterinary Science \& Research}

The authors are also grateful to Gulnaz Vafina for skill assistance and Julia Romanova for her kind assistance in MALDI-TOF mass spectrometry.

\section{References}

1. Chen C, Krause K, Pettitt B (2009) Advantage of Being a Dimer for Serratia marcescens Endonuclease. J Phys Chem 113(2): 511-521.

2. Benedik M, Strych U (1998) Serratia marcescens and its extracellular nuclease. FEMS Microbiology Letters 165(1): 1-13.

3. Trifonova E, Saveleva A, Romanova A, Filipenko M, Sapotckii V, et al. (2015) Transgenic expression of Serratia marcescens native and mutant nucleases modulates tobacco mosaic virus resistance in Nicotiana tabacum L. Genetika 51(7): 835-840.

4. Berkmen M, Benedik M (2002) Multi-Copy Repression of Serratia marcescens nuclease expression by dini. Current Microbiology 44: 44-48.

5. Miller M, Tanner J, Alpaugh M, Benedik M, Krause K (1994) 2.1 A structure of Serratia endonuclease suggests a mechanism for binding to double-stranded DNA. J Nature Struct Biol 1(7): 461-468.

6. Shlyapnikov S, Lunin V, Perbandt M, Polyakov K, Betzel $\mathrm{Ch}$, et al. (2000) Atomic structure of the Serratia marcescens endonuclease at $1.1 \mathrm{~A}$ resolution and the enzyme reaction mechanism. Acta Cryst D 56(5): 567572.

7. Miller M, Krause K (2008) Identification of the Serratia endonuclease dimer: Structural basis and implications for catalysis. J Protein Science 5(1): 24-33.

8. Romanova J, Gubskaya V, Nuretdinov I, Zainutdinova E, Filimonova M (2017) Analysis of the Mechanism of Mg2+ Action on the RNase Activity of Serratia marcescens. Bionanoscience 7(2): 276-283.

9. Friedhoff P, Kolmes B, Gimadutdinow O, Wende W, Krause $\mathrm{K}$, et al. (1996) Analysis of the mechanism of the Serratia nuclease using site-directed mutagenesis. Nucleic Acids Research 24(14): 2632-2639.

10. Nestle M, Roberts W (1969) An extracellular nuclease from Serratia marcescens. I. Purification and some properties of the enzyme. J Biol Chem 244(19): 52135218.

11. Leshchinskaya I, Balaban N, Egorova G, Taniashin V, Tretiak $\mathrm{T}$ (1974) Isolation and characterization of highly purified preparation of nuclease from Serratia marcescens. Biochemistry (Moscow) 39(11): 95-100.

12. Biedermann K, Jepsen P, Riise E, Svendsen I (1989) Purification and characterization of a Serratia marcescens nuclease produced by Escherichia coli. Carlsberg Res Commun 54: 17-27.

13. Pedersen J, Filimonova M, Roepstorff P, Biedermann K (1993) Characterization of Serratia marcescens nuclease isoforms by plasma desorption mass spectrometry. BBA 1202(1): 13-21.

14. Friedhoff P, Meiss G, Kolmes B, Pieper U, Gimadutdinow O, et al. (1996) Kinetic analysis of the cleavage of natural and synthetic substrates by the Serratia nuclease. Eur J Biochem 241(2): 572-580.

15. Filimonova M, Gubskaya V, Nuretdinov I, Benedik M, Bogomol'naya L, et al. (1997) Isoforms of Serratia marcescens nuclease. The role of $\mathrm{Mg} 2+$ in the hydrolysis mechanism. Biokhimiya 62(9): 983-988.

16. Filimonova M, Garusov A, Smetanina T, Andreeva M, Bogomol'naya L, et al. (1996) Isoforms of Serratia marcescens nuclease. Comparative analysis of the substrate specificity. Biokhimiya 61(10): 1800-1806.

17. Filimonova M, Gubskaya V, Nuretdinov I, Benedik M, Cherepanova N, et al. (2001) Study of the Mechanism of Action of p-Chloromercuribenzoate on Endonuclease from the Bacterium Serratia marcescens. Biochemistry (Moscow) 66: 323-327.

18. Filimonova M, Gubskaya V, Nuretdinov I, Leshchinskaya I (2003) Action of hexaaminecobalt on the activity of Serratia marcescens nuclease. BioMetals 16: 447-453.

19. Romanova J, Filimonova M (2012) The Effects of Addition of Mononucleotides on Sma nuc Endonuclease Activity. The Sci World J 7: 454176.

20. Filimonova M, Gubskaya V, Nuretdinov I (2014) Some features of hydrolysis of the hybrid B-Z- form DNA by Serratia marcescens nuclease. OnLine J Biol Sci 14(3): 181-187.

21. Detinenko LD, Klimenko VP, Podgornii VF, Alikin YuS, Masichova VI, et al. (1995) "Endoglyukin" means for the prevention and treatment of viral diseases of bees and stimulation of the development of bee colonies. Patent of Russian Federation no. 2038776.

22. Khismatullina N, Ivanov A, Martynova E, Mironov A, Khaiboullina S, et al. (2014) Nuclease Composition with Anti-Rabies Activity. Journal of pure and applied microbiology 8 (2): 499-504. 


\section{Open Access Journal of Veterinary Science \& Research}

23. Vafina G, Zainutdinova E, Bulatov E, Filimonova MN (2018) Endonuclease from Gram-Negative Bacteria Serratia marcescens is as Effective as Pulmozyme in the Hydrolysis of DNA in Sputum. Frontiers in Pharmacolog 9: 1-8.

24. Gabdullina GK (1980) The effect of Serratia marcescens nuclease on cells and the growth of Erlich ascites tumor. $\mathrm{PhD}$ thesis. Institute of Oncology Problems by Kavetskii RE, Academy of Science of Ukrainian SSR.

25. Elmira F Zainutdinova, Ekaterina A Naumenko, Ekaterina Martinova, Maria N Filimonova (2015) Combined Effect of Diluted Betadine and Serratia marcescens Nuclease on Viability of Rat Hepatoma Cells. Research Journal of Pharmaceutical, Biological and Chemical Sciences 6: 1637-1647.
26. Vafina G, Bulatov E, Zainutdinova E, Filimonova M (2016) A one-step protocol for chromatographic purification of non-recombinant exogenous bacterial enzyme: nuclease of Serratia marcescens. BioNanoSci 6: 335-337.

27. Filimonova M, Baratova L, Vospel'nikova N, Zheltova A, Leshchinskaya I (1981) Endonuclease Serratia marcescens. Enzyme characteristic. Biokhimiya 46: 1660-1666.

28. Patel S, Gheewala N, Suthar A, Shah A (2009) In-vitro cytotoxicity of solanum nigrum extract against HeLa cell line and Vero cell line. International Journal of Pharmacy and Pharmaceutical Sciences 1: 38-46.

29. Ball T, Wasmuth C, Braunagel C, Benedik M (1990) Expression of Serratia marcescens extracellular proteins requires recA. J of Bacteriology 172(1): 342-349. 